\title{
O TEXTO FRONTEIRIÇO DE GONÇALO M. TAVARES
}

\section{GONÇALO M. TAVARES: A TEXT IN BETWEEN}

\section{Maria Elisa Rodrigues Moreira* \\ Universidade Federal de Uberlândia}

RESUMO: A obra do português Gonçalo M. Tavares apresenta-se como um desafio para os estudos literários, uma vez que mescla em si distintos campos do pensamento, articulando-se como um território fronteiriço entre literatura e outras artes, entre literatura e outros saberes. Tal aspecto é evidenciado em projetos como o das Breves notas, série composta por três livros em que leitura e escrita dialogam entre si sugerindo a potência do pensamento fragmentário e indicando a impossibilidade das rígidas separações nos processos criativos.

PALAVRAS-CHAVE: Gonçalo M. Tavares. Fronteira. Limite.

ABSTRACT: The work of the Portuguese writer Gonçalo M. Tavares presents itself as a challenge to literary studies as it merges within itself distinct fields of thought, articulating as a border territory between literature and other arts, between literature and other types of knowledge. This aspect is evidenced in projects such as the Brief Notes, a three books series in which reading and writing interact suggesting the power of fragmentary thought and indicating the impossibility of rigid separations in creative processes.

KEYWORDS: Gonçalo M. Tavares. Border. Limit

* É graduada em Comunicação Social/Radialismo (1998), Mestre em Estudos Literários/Teoria da Literatura (2007) e Doutora em Estudos Literários/Literatura Comparada, pela Universidade Federal de Minas Gerais (UFMG). Desenvolve atualmente pesquisa de pós-doutoramento em Teoria Literária na Universidade Federal de Uberlândia (UFU). Uberlândia, Minas Gerais, Brasil. E-mail: elisarmoreira@gmail.com 


\section{O TEXTO FRONTEIRIÇO DE GONÇALO M. TAVARES}

São dois mundos com fronteiras pouco claras. Começas a rir e acabas a tremer de medo. E podes começar a tremer de medo e acabar a rir.

(Gonçalo M. Tavares, 2011a)

Gonçalo M. Tavares talvez seja um dos escritores contemporâneos com maior profusão de obras. Angolano-português, Tavares publicou seu primeiro livro em 2001 e, desde então, já são mais de 30 os títulos por ele criados. Com produções bastante diversificadas, as quais o próprio autor costuma agrupar em rubricas que funcionam como indicativos de projetos seriais (como $\mathrm{O}$ reino, $\mathrm{O}$ bairro, Arquivos, Investigações, entre outras), sua literatura se caracteriza por uma multiplicidade e instabilidade formal: há textos em diversos gêneros, e aqueles que dificilmente podem ser classificados em algum gênero, obras em que leitura, escrita e criação mesclam-se de maneira inextricável. É sobre um volume deste último tipo de textos do autor, textos híbridos e que parecem situar-se na fronteira entre a literatura e outras formas de pensamento e conhecimento, que se deterá a reflexão apresentada neste texto. 
Breves notas foi lançado no Brasil em 2010, numa coedição entre a Editora da UFSC e a Editora da Casa, em formato distinto daquele em que fora publicado anteriormente em Portugal. A edição portuguesa apresentou três livros em separado, lançados em épocas diferentes: Breves notas sobre ciência, em 2006; Breves notas sobre o medo, em 2007; e Breves notas sobre as ligações [Llansol, Molder e Zambrano], em 2009. A edição brasileira os reuniu em uma "caixa-estante" que funciona sob o protocolo de leitura da rubrica com a qual o autor os tinha nomeado na edição portuguesa: Enciclopédia. Além disso, a caixa traz um "Caderno de apresentação", de autoria de Julia Studart (2010), que se encarrega de apresentar autor e obra numa perspectiva crítica, e que pode funcionar como uma espécie de bússola para se transitar pelos volumes dessa "enciclopédia".

As Breves notas apresentam, já num primeiro contato, alguns elementos que provocam estranhamentos e mobilizam o pensamento, suscitando diversas questões, as quais pontuo e com algumas das quais procurarei dialogar, e que certamente merecerão desdobramentos posteriores. O primeiro desses elementos é a "classificação" dos três distintos volumes sob a rubrica "enciclopédia", e as implicações que esse norte coloca sobre a leitura: o que é uma enciclopédia e como se deve "lê-la"? Ou melhor, como se consulta uma enciclopédia, já que tradicionalmente elas não são construídas para a leitura integral? A prática enciclopédica está intimamente ligada às reflexões acerca do acúmulo e da classificação: desde tempos muito remotos, os homens buscavam reunir num mesmo local os conhecimentos sobre o mundo que tinham à sua disposição, organizando-os de acordo com critérios taxonômicos que possibilitassem sua organização no espaço da enciclopédia. Conforme Olga Pombo,

A enciclopédia apresenta-se como a exposição da totalidade do saber adquirido pela humanidade até um determinado momento. Ela está orientada por uma pretensão à exaustividade. Trata-se, invariavelmente, de uma obra mais ou menos volumosa que apresenta, sem pretensões de originalidade, um panorama que se pretende completo, imparcial e objectivo do conjunto dos 
conhecimentos disponíveis numa determinada época. (POMBO, 2006a, p. 180).

Passando por modelos e tendências diferentes ao longo da história (POMBO, 2006b), a prática enciclopedista afirmou-se na época moderna, em especial com os enciclopedistas franceses e o monumental projeto de sua Encyclopédie, publicada entre os anos de 1751 e 1772, na qual se procurava não apenas "compor um inventário de informações e referências", mas também delinear os caminhos para a construção de "um verdadeiro sistema unificado de conhecimentos" (MACIEL, 2009, p. 23). A ideia de um livro total, portanto, no qual possa ser acumulado e organizado todo o conhecimento do mundo, associa-se ao sentido etimológico da palavra enciclopédia, que remete "ao círculo perfeito do conhecimento", ainda que hoje essa concepção de fechamento seja questionada, por exemplo, pela ideia de "enciclopédia aberta" de Italo Calvino (1995) ou por sua aproximação ao modelo hipertextual (POMBO, 2006c).

O segundo elemento que me interessa destacar, e que está bastante articulado ao anterior, é o material que irá constituir essa "enciclopédia": como pensar as "notas" que conformam esse texto tão diverso, em sua brevidade, e em seu flerte com o ensaio e o "caderno de notas", ou seja, uma espécie de diário intelectual? Ou, para retomar um termo relevante aos estudos literários e à filosofia, como pensar o texto de Gonçalo $\mathrm{M}$. Tavares a partir de seu caráter de "fragmento"? O próprio Tavares ressalta esse aspecto em sua produção, afirmando gostar "da ideia do livro como uma espécie de tijolo, que tem vida própria, mas ao mesmo tempo, junto com outros tijolos, permite construir algo" (TAVARES, 2011).

Remetendo diretamente ao romantismo alemão, o fragmento aponta para inúmeras possibilidades de leitura (com Benjamin e com Blanchot, por exemplo) por vezes não pacíficas, dentre as quais destaco a pontuada por Philippe Lacoue-Labarthe e Jean-Luc Nancy em L’Absolu Littéraire (2004). Tratando de uma "exigência fragmentária", os autores vão além da caracterização de um possível gênero para refletir sobre diversos dos traços do fragmento em sua íntima relação com as produções românticas, articulando literatura, filosofia e conhecimento de maneira bastante complexa. 
Algumas dessas considerações parecem-me bastante produtivas se pensadas como um possível protocolo de leitura das Breves notas, as quais destaco nas palavras dos próprios autores:

[...] o relativo inacabamento ("ensaio") ou ausência de desenvolvimento discursivo ("pensamento") de cada uma de suas peças; a variedade e a mistura dos objetos que podem ser tratados por um mesmo conjunto de peças; a unidade do conjunto, por outro lado, como constituída de certa maneira fora da obra, no sujeito que se dá a ver aí ou no juízo fornecido por suas máximas. (LACOUE-LABARTHE; NANCY, 2004, p. 2).

Como terceiro elemento a destacar aponto a relação intrínseca entre leitura, escrita e criação que é tramada por Tavares nas breves notas que compõem essa sua enciclopédia: como refletir sobre uma escrita que, a todo momento, explicita as leituras que lhe conformam, numa mescla de ficção/ reflexão que por vezes tem limites bastante tênues? Como pensar o que é a literatura para esse escritor que publica incessantemente, que afirma que sua escrita deriva da leitura, que diz preencher num fluxo contínuo dezenas de páginas de seus cadernos as quais, posteriormente, irá burilar até chegar ao essencial, àquilo que acredita precise e mereça ser lido, a um texto "pequeno e forte" (TAVARES, 2010d)?

Diante de todas essas inquietações, que certamente pairam sobre a leitura aqui proposta, o aspecto que me interessa ressaltar diz respeito ao título dado a este texto e ao recorte que ele provoca sobre as notas de Gonçalo M. Tavares, estabelecendo outro possível protocolo de leitura: o da fronteira. O que significa pensar o texto desse escritor binacional (lembremos que ele nasceu em Luanda, Angola, mas viveu em Portugal desde os dois anos de idade, sendo conhecido e fazendo-se conhecer como escritor português) sob o signo da fronteira? Pensar os "cadernos de Gonçalo M. Tavares" que irão compor essas Breves notas, em relação com outras de suas produções, é pensar sobre as relações entre a literatura e o mundo, a literatura e a ciên- 
cia, a literatura e a filosofia, enfim, sobre as fronteiras de um pensamento literário que não se quer deixar aprisionar.

Em reflexão acerca das fronteiras e dos limites, palavras que se aproximam em seu campo semântico mas que marcam sutis diferenças de percepção, Cássio Hissa aponta para uma imagem conceitual da fronteira que se aproxima da leitura que intento fazer das Breves notas de Gonçalo Tavares como textos fronteiriços, dando indícios do protocolo de leitura que me proponho a seguir. Assim diz ele:

Para além da linha que demarca, é exatamente a fronteira que explicita a amplitude ou a complexidade do que não foi arquitetado para ser contido ou confinado. O que foi concebido para "por fim", para delimitar territórios com precisão como se fosse uma linha divisória, espraia-se em uma zona de interface e de transição entre estes dois mundos tomados como distintos. (HISSA, 2006, p. 35-36)

Os textos de Tavares não se deixam aprisionar, ainda que pareçam evidenciar o trânsito entre mundos que costumamos entender como diversos, como o seriam a literatura e a reflexão, a criação e a produção intelectual, a arte e a ciência, a escrita e a leitura. Mas esses textos, apesar de marcados pelo limite, por esse "algo que se insinua entre dois ou mais mundos, buscando a sua divisão, procurando anunciar a diferença e apartar o que não pode permanecer ligado" (HISSA, 2006, p. 19), estão contaminados pela ideia da fronteira, dessa divisão que "está voltada para fora como se pretendesse a expansão daquilo que lhe deu origem", essa zona de transição que mais "movimenta a reflexão sobre o contato e a integração" do que a "distância e a separação" (HISSA, 2006, p. 34).

É, portanto, pensando no "contato" e na "integração" entre o diverso, mais que naquilo que nele provoca o distanciamento, que conduzo minha leitura das Breves notas de Tavares, e aqui já encontro alguns elementos para pensar as questões com que abri este texto: a enciclopédia, o fragmento, a escrita da leitura. Os três volumes que compõem a série são bastante diversos entre si, 
ainda que se possa neles perceber uma intenção comum, um fio capaz de lhes garantir certa unidade. Breves notas sobre ciência, de 2006, é o que mais parece se constituir, realmente, de notas breves, as quais gravitam em torno de algumas palavras/categorias nucleares para a ciência. Às vezes remetendo a algum autor referencial da epistemologia ou da metodologia científica, outras vezes parecendo tratar-se de reflexões motivadas pela área de maneira menos específica, as notas de Tavares são ao mesmo tempo reflexivas e poéticas, estéticas e políticas. Breves notas sobre o medo, de 2007, por sua vez, traz textos um pouco menos "breves" e cuja ligação com a temática título, o medo, por vezes parece difícil de ser percebida, pois que muito mais subjetiva: há textos sobre a saúde, a velhice, a perda da beleza, a perda da sanidade, a solidão, a falta de expectativas, o desalento, a descrença... A classificação, imposta pelo próprio autor ao inserir esses fragmentos no livro em questão, já nos indica a arbitrariedade e a subjetividade dos processos de determinação de limites que pretendem agrupar, em um mesmo território, elementos que se julgam próximos, semelhantes. A unidade dos fragmentos chega, pois, de "fora da obra", da organização a eles dada pelo escritor. Com Breves notas sobre as ligações (Llansol, Molder e Zambrano), de 2009, Gonçalo Tavares parece subverter a lógica que orientara a construção dos dois volumes anteriores, passando a estabelecer um diálogo explícito com breves fragmentos das três "marias" que elege como interlocutoras (Maria Gabriela Llansol, Maria Filomena Molder e María Zambrano). As ligações, aqui, apontam para inúmeras possibilidades de contato que se explicitam por meio de um percurso traçado pelo texto de Tavares junto aos textos de suas interlocutoras, e também pelo diálogo entre elas que a leitura feita pelo escritor português propicia.

Busco nos próprios textos de Tavares algo sobre as classificações, alguma reflexão que talvez auxilie na construção de um pensamento sobre sua opção serial para essas obras, a da enciclopédia. Encontro uma primeira menção, nas Breves notas sobre ciência, nas notas "Diferenças e semelhanças (1), (2) e (3)". Nelas, Tavares chega à classificação passando pela temática da diferenciação. Assim diz:

Ver as diferenças é um dos métodos. Ver as semelhanças é outro. 
O mosquito que perturba a tua harmonia de som e espaço, quando esmagado pelas tuas mãos rápidas, torna-se silencioso - como as mãos depois da acção. Após deitares fora o mosquito a harmonia de som e espaço regressa. Mas não julgues que é definitiva, a harmonia. Sabes bem que não.

(TAVARES, 2010a, p. 12)

E continua: "Podemos matar o mosquito ou apontar para ele e dizer: Mosquito. As classificações e as categorias começam na desarmonia" (TAVARES, 2010a, p. 13). Para classificar, portanto, seria preciso que se encontrasse a diferença, algo que surgisse como um estranho num conjunto de similaridades, e a ele impusesse uma mudança. Categorizar e classificar, assim, seriam ações baseadas na nomeação daquilo que difere e em sua inserção num conjunto que se separa do outro por um limite imposto. Classificar um texto para incluí-lo em determinado livro, e não em outro, é uma forma de marcar semelhanças e diferenças. Classificar um livro para incluí-lo em uma série, e não em outra, é fazer o mesmo, mas lembrando-se de que, entre os livros que a compõem, a diferença está também presente.

As palavras de Tavares funcionam, para usar a expressão de Cássio Hissa, como "frases-fronteira", ou seja, em lugar de serem "ideias-limite", que sugerem o fechamento, elas são "sentenças-abertura", frases que nos fazem "pensar o mundo e todas as possibilidades de percebê-lo também a partir dos lugares, das instituições, dos sujeitos" (HISSA, 2011, p. 133). Como fronteiras, mais abrem possibilidades de respostas e sugerem novas questões que respondem às interrogações anteriormente colocadas.

Persisto na busca pela classificação na obra de Tavares, transitando por suas breves notas. Ainda dentre aquelas dedicadas à ciência, encontro uma nota intitulada "Classificação", que cito na íntegra:

Classificar é uma poesia unânime.

[Inútil, portanto, para um indivíduo.]

(TAVARES, 2010a, p.40) 
Nesta tão breve nota, questões inúmeras parecem brotar e ramificar-se de encontro à reflexão aqui proposta: poesia e ciência são aproximadas por Tavares de uma maneira distinta, que nos faz rever os territórios destinados comumente a uma e a outra, fazendo assim com que ampliemos a zona fronteiriça que se estende entre ambas. Classificar, ato classicamente vinculado à ciência e às atividades racionais, torna-se nas palavras do escritor português poesia, e não uma poesia qualquer, mas uma poesia unânime, ou seja, uma poesia que não sofre questionamentos, uma poesia aceita por todos, uma poesia que exprime concordância. Uma poesia da semelhança, poderíamos pensar. E, porque poesia, classificar mostra-se também como atividade inútil para o ser humano (ou, se quisermos, podemos inverter a ordem e alterar seu sentido: porque inútil para o indivíduo, o ato de classificar pode ser tido como um ato poético).

O que dizer, então, de um escritor que classifica suas obras ao inseri-las em breves séries como as que citamos anteriormente? Qual sua intenção, talvez menos óbvia do que a de indicar um protocolo de leitura e uma aproximação/afastamento entre elas? Indicar sua arbitrariedade, sua inutilidade, sua poeticidade, talvez? E se esse escritor, mesmo criando pequenos territórios circunscritos no terreno mais amplo de sua obra, brinca continuamente com as fronteiras entre os gêneros e as tradicionais classificações literárias, escrevendo contos, notas, romances, poesia, e deixando tudo a transitar por sobre os limites que ele mesmo estabelece, indicando assim o quão imprecisos eles são? Se ele ressalta, insistentemente, nas inúmeras entrevistas que concede, ser avesso às classificações e aos gêneros em literatura?

Volta-se assim, uma vez mais, à questão das fronteiras e dos limites, diretamente relacionada à ideia da classificação, questão que irá permear as breves notas tavarianas, contribuindo para a conformação de uma imagem de texto fronteiriço mais complexa, espessa e porosa. Continuando a percorrer as Breves notas sobre ciência, deparo-me com a nota intitulada "Investigações e desequilíbrio", que assim se apresenta:

Debruçai-vos sobre o futuro: no limite só os pés permanecem sobre o solo, a cabeça foge para a frente. Investigar sem desequilíbrio é avançar em cima da 
lama: alguém se afunda.

(TAVARES, 2010a, p. 36)

O limite, aqui, nos remete ao tempo, passado, presente e futuro, e provoca o desequilíbrio. Para avançar em direção ao futuro, se os pés permanecem ali, na linha que demarca, a cabeça, a outra extremidade do corpo, seu limite superior, precisa inclinar-se para a frente. Para ultrapassar o limite, é preciso gerar o desequilíbrio, desestabilizar os territórios, fazer a transição entre o diverso e instalar-se num terreno movediço que não está nem em um nem em outro lado da linha divisória, mas justamente aí, na fronteira por ela instituída.

O pensamento sobre o limite continua a se espraiar pelas notas tavarianas, como em "O Novo e os especialistas", nota subsequente à apresentada acima:

Só acrescentas algo ao Mundo 1 - quer este seja uma disciplina científica ou apenas uma ideia - se trouxeres algo do Mundo 2.

Dito de outro modo, e sendo óbvio para avançar:

Nada que pertença ao Mundo 1 é novo para o Mundo 1. Queres trazer-te o novo? Sai de ti.

Queres trazer algo de novo a esta caixa quadrada de 1 metro por 1 metro?

Então procura algo fora dela.

(TAVARES, 2010a, p. 37)

Aí está o pensamento da fronteira, um lugar de trânsito, um lugar transformado em "passagem obrigatória" (HISSA, 2006, p. 44) no qual circulam as novidades, no qual aquilo que é diferente em relação a um determinado território se liga a ele, acrescentando-lhe algo e possibilitando, assim, o avanço, o pensamento, a mudança. Afinal, como afirma o escritor nas Breves notas sobre as ligações, "Só começamos a estar vivos quando deixa de ser fácil” (TAVARES, 2010c, p. 21), e só deixa de ser fácil quando saímos de nossa zona de conforto, do limite em que nos cercamos daquilo que nos é conhecido, daquilo que se assemelha, e nos arriscamos por um terreno dis- 
tinto; quando deixamos que a desarmonia persista; quando não matamos o mosquito que nos incomoda; quando abandonamos o Mundo 1 e vamos buscar nas veredas do Mundo 2 algo que nos permita mudar, que nos desequilibre, que propicie o avanço. "Pois vida é esta incapacidade de um órgão desligar-se do outro", diz Tavares fazendo ecoar a frase de María Zambrano, a respeito da qual comenta:

Incapacidade de desligação. Estou vivo: impossível separar-me.

Ou: estou vivo: estou obrigado a ligar-me.

(TAVARES, 2010c, p. 31)

Impossível a separação, impossível o limite pensado apenas como linha que distingue. Afinal, se "o limite insinua a presença da diferença e sugere a necessidade da separação", ele é também aquilo "que se coloca entre dois ou mais mundos, para que suas diferenças possam ser compreendidas", sendo, nesse caso, "apenas disfarce", pois "concebido como instrumento do saber" (HISSA, 2006, p. 19). A necessidade de ligação faz do limite disfarce. Retomo, a esse respeito, as palavras de Gonçalo Tavares:

As coisas aproximam-se. E mesmo: as coisas afastam-se. Porque o afastar é ainda um movimento de ligação, movimento que prova a existência de ligações com o outro; se me afasto é porque existe algo de que me afasto.

Estou vivo porque me ligo e estou vivo porque me afasto. (TAVARES, 2010c, p. 32, grifos do original)

A fronteira não deve separar: ela pode afastar, criando entre territórios distintos uma superfície ampliada, espessada, superfície que, no entanto, marca ainda a ligação entre os dois universos. O um só existe em relação ao outro, que assim está intrinsecamente ligado a ele. É preciso encontrar a forma da ligação, e esta pode se dar na fronteira espessa que é lugar de troca, de intercâmbio. A fronteira pode ser, assim, o lugar do desequilíbrio produtivo. 
É interessante, nesse sentido, trazer para este diálogo outra reflexão do próprio Tavares, presente em "De arte e de ciência: o golpe decisivo com a mão esquerda", em que o escritor português afirma:

[...] nós deveríamos, na ciência e nas artes, muitas vezes, tentar metodologias que não são parecidas conosco, e que nos são estranhas. Com elas lidaríamos com dificuldade, mas, provavelmente, encontraríamos resultados surpreendentes. [...] Literariamente, procuro fazer um pouco isso. Quando sinto que domino um espaço, eu procuro localizar um lugar onde eu não me sita seguro e penso ser, esta, uma boa estratégia.

(TAVARES; HISSA, 2011, p. 127-128)

Buscar o lugar do desequilíbrio, da insegurança. Buscar a fronteira como zona de produção entre mundos, na qual é possível mergulhar no Mundo 1 e no Mundo 2, cabeça de um lado, pés do outro, e o corpo ali, naquele espaço híbrido, transicional, que é o que garantirá o movimento, o avanço. Se pensamos que a fronteira é um lugar "entre" outros, poderíamos pensar nela como um intervalo? Os intervalos aparecem, em nota de mesmo título, nas Breves notas sobre o medo, com a seguinte caracterização:

Não colecionamos transições - caminhadas entre um sítio e outro. Tal incapacidade, pois disso se trata, é, entre as várias, uma das que mais nos menoriza. Memorizamos tranquilamente - nos nervos internos treinados para tal tarefa - um sítio e outro, um sentimento e o que surge a seguir, os amantes consecutivos, um dia e o seguinte [domingo, segunda], mas o que está entre o visível, o nomeável e o memorizável perde-se - sem textura nem ocupação mínima do espaço que permita tornar credível, aos olhos dos outros, a sua coleção. E o que não podemos mostrar não existe.

(TAVARES, 2010b, p. 13) 
Seria, pois, a escrita na fronteira uma forma de enfrentar o medo, o medo daquilo que nos torna menores, daquilo que não conseguimos identificar ao certo, daquilo que nos causa a dúvida? Escrever na fronteira seria uma forma de resistência daquilo que não se pode mostrar, mas que existe e deixa suas marcas, ainda que não consigamos colecioná-las? Poder-se-ia pensar que a escrita na fronteira é tomada por Gonçalo Tavares como um método capaz de garantir a estranheza, como o método que, lendo Walter Benjamin pelos olhos de Maria Filomena Molder, Tavares aponta "como aquilo que se faz depois de ter tropeçado; ou: o movimento não planeado, espontâneo; para não cair depois de um desequilíbrio" (TAVARES, 2010c, p. 73)?

Parece que esse texto fronteiriço, que escapa às tentativas de delimitação, que brinca com o limite e faz dele o disfarce de uma larga fronteira, que insiste em se espraiar para ambos os lados da linha divisória, é uma espécie de metodologia de escrita que garante o equilíbrio no necessário desequilíbrio do estranhamento. Esse texto fronteiriço parece poder garantir à ficção ser ao mesmo tempo um movimento e uma imobilidade, conforme hipóteses pelo autor delineadas nas Notas sobre as ligações. Escrevendo na fronteira, Gonçalo M. Tavares amplia o território da literatura, fazendo com que os limites que para ele tradicionalmente traçamos avancem rumo a outros terrenos, pantanosos, escorregadios, nos quais não se sabe ao certo o que encontrar. Com esse movimento, ele faz com que a literatura deixe de ser fácil, faz com que se torne viva, com que se alegre. Afinal, "só quem é alegre arrisca” (TAVARES, 2010a, p. 50).

\section{REFERÊNCIAS}

CALVINO, Italo. Seis propostas para o próximo milênio. Tradução de Ivo Barroso. 2. ed. São Paulo: Companhia das Letras, 1995.

HISSA, Cássio Eduardo Viana. A mobilidade das fronteiras: inserções da geografia na crise da modernidade. Belo Horizonte: Ed. UFMG, 2006. 
HISSA, Cássio E. Viana (Org.). Conversações: de artes e de ciências. Belo Horizonte: Ed. UFMG, 2011.

LACOUE-LABARTHE, Philippe; NANCY, Jean-Luc. A exigência fragmentária. Tradução de João Camillo Penna. Terceira Margem, Rio de Janeiro, n. 10, 2004. Disponível em: www.letras.ufrj.br/ciencialit/terceiramargemonline/numero10/v.html. Acesso em: 10 jan. 2014.

MACIEL, Maria Esther. As ironias da ordem: coleções, inventários e enciclopédias ficcionais. Belo Horizonte: Ed. UFMG, 2009.

POMBO, Olga. O projecto enciclopedista. In: POMBO, Olga; GUERREIRO, António; ALEXANDRE, António Franco (Ed.). Enciclopédia e hipertexto. Lisboa: Duarte Reis, 2006a. p. 180-193.

. Para uma história da ideia de enciclopédia. Alguns exemplos. In: POMBO, Olga; GUERREIRO, António; ALEXANDRE, António Franco (Ed.). Enciclopédia e hipertexto. Lisboa: Duarte Reis, 2006b. p. 194-251.

. O hipertexto como limite da ideia de enciclopédia. In: POMBO, Olga; GUERREIRO, António; ALEXANDRE, António Franco (Ed.). Enciclopédia e hipertexto. Lisboa: Duarte Reis, 2006c. p. 266-288.

STUDART, Júlia. O impacto da impressão, as breves notas (caderno de apresentação). Florianópolis: Ed. UFSC/Ed. da Casa, 2010.

TAVARES, Gonçalo M. Breves notas sobre ciência. Florianópolis: EdUFSC/ Ed. da Casa, 2010a.

. Breves notas sobre o medo. Florianópolis: EdUFSC/Ed. da Casa, 2010b.

. Breves notas sobre as ligações (Llansol, Molder e Zambrano). Florianópolis: EdUFSC/Ed. da Casa, 2010c. 
. O romance ensina a cair. Entrevista. Ipsilon, Lisboa, 27 out. $2010 \mathrm{~d}$. Disponível em: http://ipsilon.publico.pt/livros/texto.aspx?id=268246. Acesso em 10 dez. 2013.

. Gonçalo M. Tavares: A moralidade da máquina está a alastrar pela sociedade. Entrevista. Euronews, Lyon, 31 maio 2011a. Disponível em: http://pt.euronews.com/2011/05/31/goncalo-m-tavares-a-moralidade-da-maquina-esta-a-alastrar-pela-sociedade/. Acesso em 10 out. 2013.

Gonçalo M. Tavares e a glória do português. Entrevista. Veja Meus Livros, São Paulo, 03 set. 2011b. Disponível em: http://veja.abril.com.br/ blog/meus-livros/entrevista/goncalo-m-tavares-e-a-gloria-do-portugues/. Acesso em 05 out. 2013.

. HISSA, Cássio E. Viana. De arte e de ciência: o golpe decisivo com a mão esquerda. In: HISSA, Cássio E. Viana (Org.). Conversações: de artes e de ciências. Belo Horizonte: Ed. UFMG, 2011. p. 125-150. 